\title{
Urban air pollution and cardiopulmonary ill health: a 14.5 year time series study
}

\author{
G J Prescott, G R Cohen, R A Elton, F G R Fowkes, R M Agius
}

\begin{abstract}
Objectives-To examine possible associations between daily concentrations of urban air pollutants and hospital emergency admissions and mortality due to cardiac and pulmonary disease.

Methods-A time series study was conducted in the City of Edinburgh, which has a population of about 450000 . Poisson log linear regression models were used to investigate the relation of the daily event rate with daily air pollution concentrations of sulphur dioxide $\left(\mathrm{SO}_{2}\right)$ and black smoke from 1981 to 1995 , and of nitrogen dioxide $\left(\mathrm{NO}_{2}\right)$, ozone $\left(\mathrm{O}_{3}\right)$, carbon monoxide (CO), and particulate matter $\left(\mathbf{P M}_{10}\right)$ from 1992 to 1995 . Adjustments were made for seasonal and weekday variation, daily temperature, and wind speed.
\end{abstract}

Results-The most significant findings were positive associations over the period 1981-95 between black smoke as a mean of the previous three days and daily all cause mortality in people aged $\geqslant 65$, and respiratory mortality also in this age group $(3.9 \%$ increase in mortality for a $10 \mu \mathrm{g} / \mathrm{m}^{3}$ increment in black smoke). For hospital emergency admissions between 1992 and 1995 the two most significant findings $(p<0.05)$ were for cardiovascular admissions of people aged $\geqslant 65$ which showed a positive association with $\mathbf{P M}_{10}$ as a mean of the 3 previous days, and a negative association with $\mathrm{O}_{3}$ as a mean of the previous three days. Analyses of outcomes based on linkage with previous cardiorespiratory emergency admissions did not show substantially different results.

Conclusion-These data suggest that in the City of Edinburgh, after correction for confounders, there was a small but significant association between concentrations of black smoke and respiratory mortality in the older age group, probably attributable to higher pollution levels in the early part of the study period. There were also generally weak and variable associations between day to day changes in concentrations of urban air pollutants at a single central point and emergency hospital admission rates from cardiac and respiratory disease.

(Occup Environ Med 1998;55:697-704)

Keywords: urban air pollution; mortality; morbidity

Adverse influences of air pollution on health may include increased mortality, as shown by cohort studies. ${ }^{1}$ Time series studies can investigate the extent to which day to day variations in urban air pollution concentrations may be associated with changes in morbidity, indicated for example by emergency admissions to hospital, and changes in mortality from cardiac or respiratory disease. Thus correlations between $\mathrm{SO}_{2}$ and other concentrations of pollutants and adverse health outcomes have been shown in Athens, ${ }^{2}$ Birmingham, ${ }^{34}$ and London. ${ }^{5}$ The United Kingdom national air quality strategy defines the legal standards relating to the quality of air as based on the assessment of the effects of each pollutant on public health. ${ }^{6}$ Thus although time series studies might consider only a harvesting effect ${ }^{7}$ it is still important to conduct an adequate number of appropriate studies in the United Kingdom to complete this health risk assessment reliably. We report on a 14.5 year time series study in Edinburgh, Scotland. This duration was designed to provide for a better resolution of temporal and other confounding variables. Edinburgh is a smaller conurbation than those previously reported in the United Kingdom, and has relatively lower concentrations of pollutants than other cities where similar time series studies have been reported. ${ }^{489}$ However, the duration of the series gives aspects of this study statistical power similar to that in an urban population of a million for 7 years.

\section{Methods}

STUDY AREA

The city of Edinburgh has a population of about 450000 and comprises an area of about $250 \mathrm{~km}^{2}$ in south east Scotland. The conurbation, which is part of the Lothian Region with a total population of about 750000 , is well delineated to the north by the sea, and in the other directions is roughly demarcated by a bypass road. Health outcome data were assembled for the three surrounding districts of East Lothian, Mid-Lothian, and West Lothian which include rural areas and some small and medium sized towns, but in this paper only outcomes for the Edinburgh city population data were used to increase the homogeneity of the pollution experienced, relative to monitoring in the urban centre.

AIR POLLUTION AND METEOROLOGICAL DATA

Two study periods were used: a long period, from January 1981 to June 1995 inclusive, for which only measurements of black smoke and sulphur dioxide $\left(\mathrm{SO}_{2}\right)$ were available. Black smoke was determined by drawing a measured amount of air through a filter paper resulting in a smoke stain, the intensity of which was assessed with a reflectometer. The reflected light was measured by a photo cell with less light being reflected from darker stains. The 
Table 1 Summary statistics for daily measurements of health outcomes, two pollutants, and meteorological variables, in the city of Edinburgh, over long and short study periods

\begin{tabular}{|c|c|c|c|c|c|c|c|c|}
\hline & \multicolumn{4}{|c|}{ Long period 1981-95 } & \multicolumn{4}{|c|}{ Short period $1992-5$} \\
\hline & Mean & $S D$ & Min & Max & Mean & $S D$ & Min & $\operatorname{Max}$ \\
\hline \multicolumn{9}{|l|}{ Deaths/day: } \\
\hline \multicolumn{9}{|l|}{ All causes: ${ }^{\star}$} \\
\hline All ages & 15.1 & 4.4 & 2 & 45 & 14.3 & 4.1 & 3 & 30 \\
\hline$<65$ & 2.9 & 1.8 & 0 & 11 & 2.5 & 1.6 & 0 & 8 \\
\hline$\geqslant 65$ & 12.2 & 4.0 & 1 & 38 & 11.8 & 3.8 & 3 & 25 \\
\hline \multicolumn{9}{|l|}{ Cardiovascular:^ } \\
\hline \multirow{2}{*}{\multicolumn{9}{|c|}{ Respiratory:* }} \\
\hline & & & & & & & & \\
\hline$\geqslant 65$ & 1.4 & 1.3 & 0 & 12 & 1.4 & 1.3 & 0 & 7 \\
\hline \multicolumn{9}{|c|}{ Emergency hospital admissions/day: } \\
\hline \multicolumn{9}{|l|}{ Cardiovascular:^ } \\
\hline$<65$ & 3.5 & 1.9 & 0 & 12 & 3.4 & 1.9 & 0 & 10 \\
\hline$\geqslant 65$ & 8.0 & 3.2 & 0 & 24 & 8.7 & 3.4 & 0 & 24 \\
\hline \multicolumn{9}{|l|}{ Respiratory:^ } \\
\hline$<65$ & 3.3 & 2.0 & 0 & 14 & 3.5 & 2.0 & 0 & 12 \\
\hline$\geqslant 65$ & 2.8 & 2.0 & 0 & 15 & 3.4 & 2.1 & 0 & 13 \\
\hline \multicolumn{9}{|c|}{ Pollutant concentrations ( $24 \mathrm{~h}$ mean): } \\
\hline Black smoke $\left(\mu \mathrm{g} / \mathrm{m}^{3}\right)$ & 12.3 & 12.8 & 1 & 194 & 8.7 & 7.6 & 1 & 68 \\
\hline $\mathrm{SO}_{2}$ (titration) (ppb) & 14.5 & 9.0 & 0 & 153 & & & & \\
\hline $\mathrm{SO}_{2}$ (UV fluorescence) (ppb) & & & & & 8.3 & 5.6 & 1 & 50 \\
\hline $\mathrm{PM}_{10}\left(\mu \mathrm{g} / \mathrm{m}^{3}\right)$ & & & & & 20.7 & 8.4 & 5 & 72 \\
\hline $\mathrm{NO}_{2}(\mathrm{ppb})$ & & & & & 26.4 & 7.0 & 9 & 58 \\
\hline $\mathrm{O}_{3}(\mathrm{ppb})$ & & & & & 14.5 & 2.3 & 1 & 37 \\
\hline $\mathrm{CO}(100 \mathrm{ppb})$ & & & & & 6.2 & 2.8 & 0 & 25 \\
\hline \multicolumn{9}{|c|}{ Meteorological variables ( $24 \mathrm{~h}$ mean): } \\
\hline Minimum temperature $\left({ }^{\circ} \mathrm{C}\right)$ & 5.6 & 4.8 & -15 & 17 & 5.0 & 4.6 & -7 & 17 \\
\hline Wind speed (knots) & 8.6 & 4.4 & 0 & 28 & 8.7 & 4.4 & 1 & 24 \\
\hline
\end{tabular}

*All causes with ICD-9 <900 (for ICD-9 definitions of cardiovascular and respiratory causes, see text).

$\mathrm{SO}_{2}$ was determined by bubbling through a weak solution of hydrogen peroxide and subsequent titration with sodium tetraborate to determine the net gaseous acidity. ${ }^{10} 11$

From October 1992 to June 1995 constituted a short study period for which additional pollutant measurements were available. An automatic air quality monitoring station in the centre of Edinburgh formed part of the Department of Environment's enhanced urban network. ${ }^{12}$ The station is sited in public gardens, but very close to a major thoroughfare. Most of the conurbation lies within $7 \mathrm{~km}$ of this site. The following pollutants were studied: nitrogen dioxide $\left(\mathrm{NO}_{2}\right)$ (by conversion to nitric oxide (NO) measured by chemiluminescence); ozone $\left(\mathrm{O}_{3}\right)$ by ultraviolet absorption; particulate matter $\left(\mathrm{PM}_{10}\right)$ by tapered element oscillating microbalance; $\mathrm{SO}_{2}$ by ultraviolet fluorescence, and carbon monoxide $(\mathrm{CO})$ by

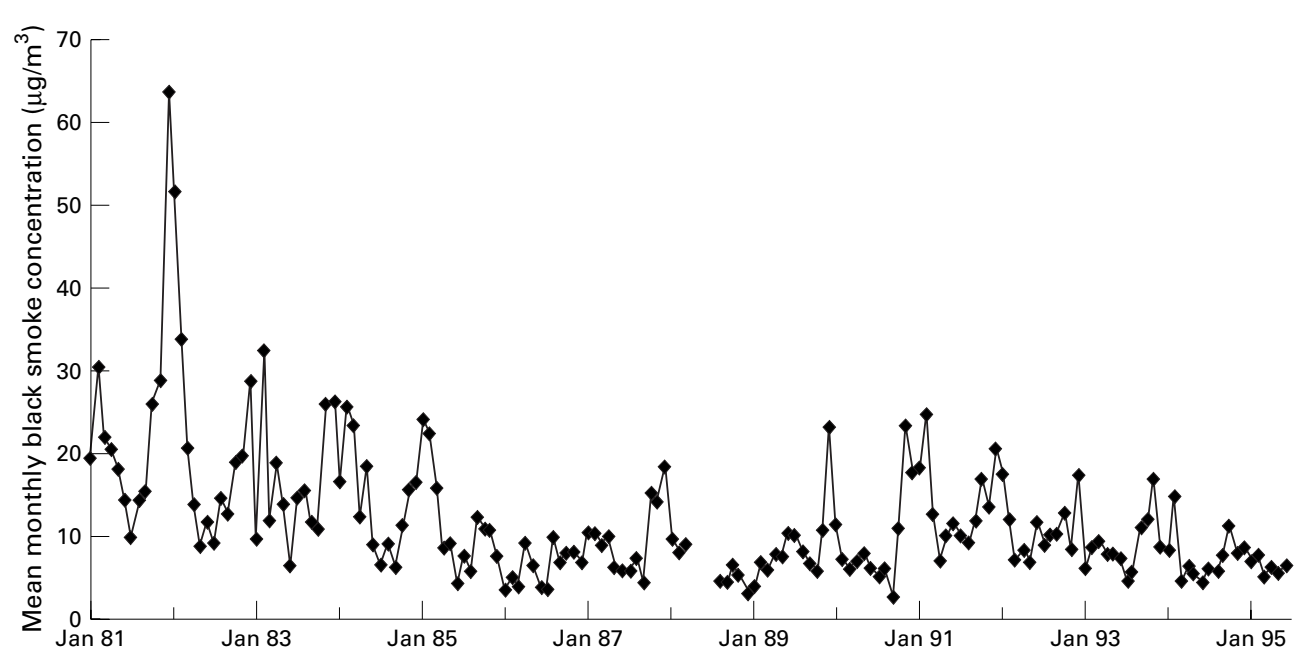

Figure 1 Black smoke concentration by date 1981-95. infrared absorption. Daily averages of hourly measurements with at least 18 hours of records in a 24 hour, midnight to midnight, period were used for these analyses.

The Meteorological Office supplied data on daily mean wind speed measured at a station at Edinburgh airport (situated $10.5 \mathrm{~km}$ west of the city centre). Daily minimum and maximum temperatures and 24 hour rainfall were taken from the meteorological station at the Edinburgh Royal Botanic Gardens (2 km north of the city centre).

\section{HEALTH OUTCOME DATA}

The type and availability of routinely collected pollution data determined the study periods. Thus, for both the long and the short periods, daily counts were obtained of the numbers of Edinburgh residents admitted to hospital as emergencies with principal discharge diagnoses of cardiovascular or respiratory disease, and the numbers of deaths from these underlying causes. Cardiovascular events were limited to those defined by the international classification of diseases 9th revision (ICD-9) codes 410414, 426-429, and 434-440, which cover cardiac and cerebral ischaemia, but exclude cerebral haemorrhage. Respiratory events were limited to codes 480-487 (pneumonia and influenza) and 490-496 (mainly asthma and chronic obstructive pulmonary disease). Analysis of all cause mortality excluding accidents (ICD9 $<900^{8}$ ) was also carried out. These data were extracted from the Scottish record linkage system, ${ }^{13}$ in which individual hospital admission and mortality records are linked algorithmically.

\section{STATISTICAL METHODS}

Separate analyses were carried out for two age groups: $<65$, and $\geqslant 65 .{ }^{14}$ For each age group and each type of health outcome Poisson log linear regression models were used to investigate the relation of the daily event rate with daily pollution levels, adjusting for trend, seasonal and weekday variation, and daily temperature and wind speed. The adjustment for trend and seasonality was accomplished by 
A

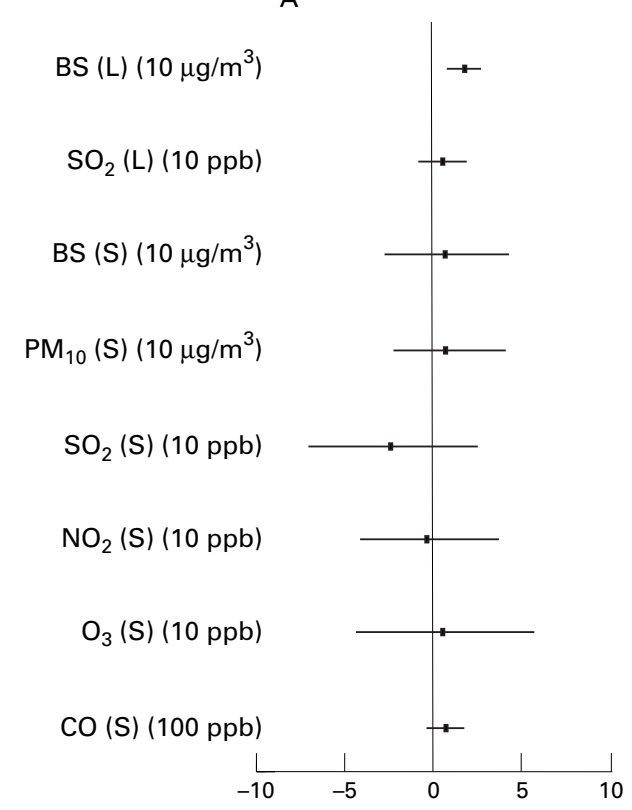

B

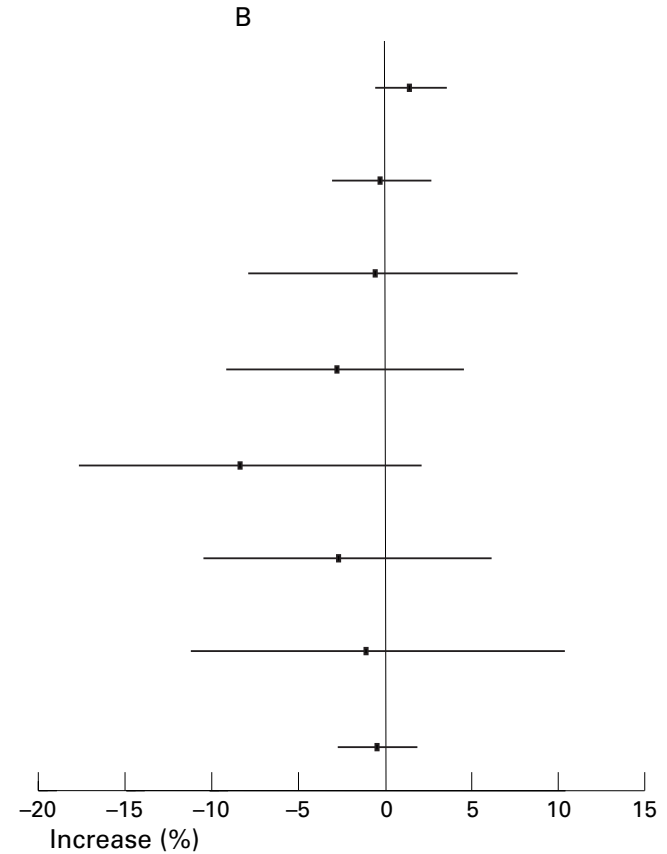

Figure 2 All cause mortality for $(A)$ the $\geqslant 65$ age group and $(B)$ the $<65$ age group. BS=black smoke; $L=$ long series 1981-95; $S=$ short series $1992-5$.

including in each model a separate dummy variable for every month in the series, so that only day to day variation within months influenced the estimated pollution-health relation. As there were large systematic differences in both mean pollution levels and daily hospital admission rates between weekdays and weekends, terms for days of the week were also included in the models. The range of daily minimum temperature was divided into eight intervals, with roughly equal numbers of days in each, and dummy variables assigned to each interval, thus avoiding the assumption of a linear or other simple functional relation between

\section{A}

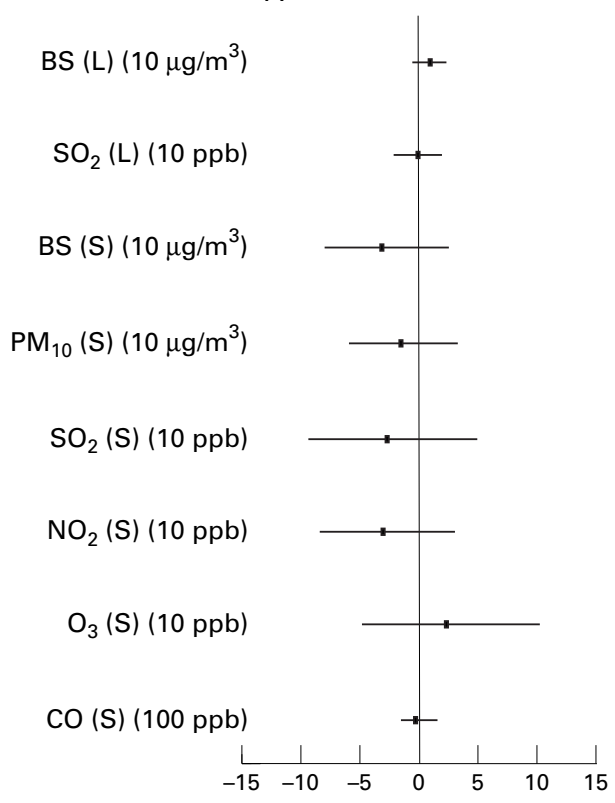

health outcomes and temperature. Daily maximum temperature was investigated initially, but was generally found to have small coefficients in the models. Wind speed was modelled as a linear term, but rainfall and relative humidity were omitted from the models as they did not have any significant effect. Each pollutant was modelled simply as a linear term. Logged base populations for each age group in each year were included as offsets ${ }^{15}$ in the model.

Separate families of models were investigated in which daily event rates were related to pollutant effects measured at lag 0 (same day), lag 1 (previous day), and as a moving mean of

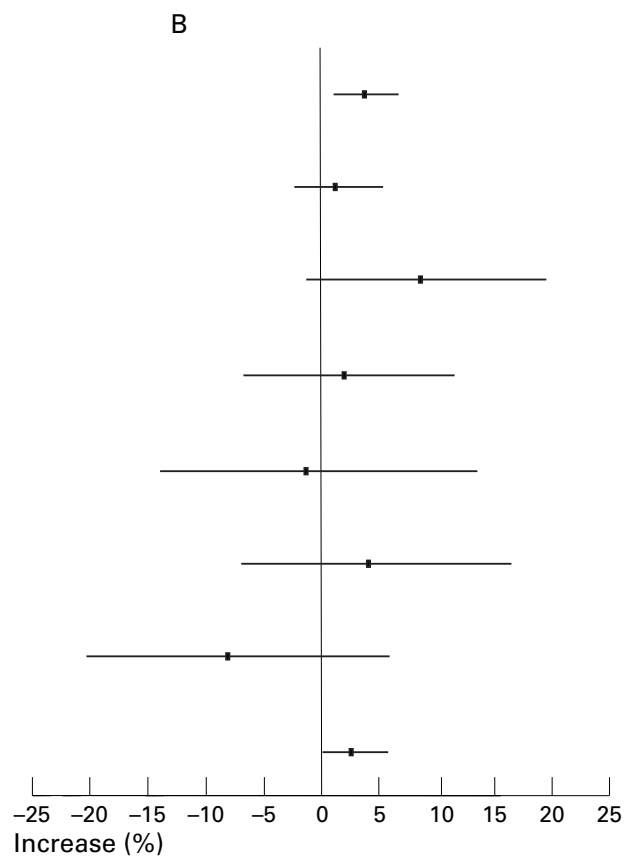

Figure 3 Mortality of the $\geqslant 65$ age group for $(A)$ cardiovascular and (B) respiratory causes. $B S=$ black smoke; $L=$ long series 1981-95; $S=$ short series $1992-5$. 
Table 2 Estimated increases (\%) in emergency cardiorespiratory hospital admissions for patients aged $\geqslant 65$ associated with an increment of 10 ppb in same day nitrogen dioxide, according to a series of models with increasing adjustment for confounders

\begin{tabular}{|c|c|c|c|c|}
\hline \multirow[b]{3}{*}{ Model } & \multicolumn{4}{|c|}{ Emergency admissions for age 65 and older } \\
\hline & \multicolumn{2}{|c|}{ Cardiovascular } & \multicolumn{2}{|c|}{ Respiratory } \\
\hline & $\begin{array}{l}\text { Increase } \\
(\%)\end{array}$ & $p$ Value & $\begin{array}{l}\text { Increase } \\
(\%)\end{array}$ & $p$ Value \\
\hline $\mathrm{NO}_{2}$ & 6.8 & 0.0001 & 15.6 & 0.0001 \\
\hline $\mathrm{NO}_{2}$ adjusted for months & 6.6 & 0.0001 & 15.0 & 0.0001 \\
\hline $\mathrm{NO}_{2}$ adjusted for months, min temp & 5.9 & 0.0002 & 11.7 & 0.0001 \\
\hline $\mathrm{NO}_{2}$ adjusted for months, min temp, wind & 10.3 & 0.0008 & 15.8 & 0.0001 \\
\hline $\begin{array}{l}\mathrm{NO}_{2} \text { adjusted for months, min temp, wind, day of } \\
\text { the week }\end{array}$ & -0.8 & 0.71 & 6.5 & 0.08 \\
\hline
\end{tabular}

Min temp=minimum temperature.

the previous three days. Separate models were first considered for each pollutant added to the core model (which contained terms for weekdays, months, minimum temperature, and wind speed). Then for each age group, health outcome, and lag, models containing all the pollutants together were considered. Goodness of fit was assessed by (a) Pearson's $\chi^{2}$ tests on the residuals; (b) residual plots to detect autocorrelation and other departures from assumptions.

To explore whether people with a higher frequency of emergency admissions might be more susceptible to the influence of pollution, the linkage of the health data set was exploited, and people were categorised according to the number of their cardiovascular and respiratory emergency admissions over the period of study. This was first undertaken for the long series, 1981-95, with black smoke and $\mathrm{SO}_{2}$ and then repeated for the short series with $\mathrm{PM}_{10}$ and $\mathrm{O}_{3}$ as these were the pollutants with which associations were found in one or more of the lag periods studied. The emergency admissions of these people were then analysed with the usual time series methods.

\section{Results}

SUMMARY STATISTICS

Table 1 shows summary statistics for daily measurements of health outcomes, the two pollutants, and meteorological variables, in the city of Edinburgh, over the long and short study periods, 1981-95 and 1992-5. The exposure variables had highly positively skewed distributions. Average levels of black smoke and $\mathrm{SO}_{2}$ were notably lower more recently than over the whole period from 1981-95. The annual average of the mean daily black smoke fell from about $23 \mu \mathrm{g} / \mathrm{m}^{3}$ in 1981 to $8 \mu \mathrm{g} / \mathrm{m}^{3}$ in 1994. The change in the black smoke concentration is shown in figure 1 where it is represented as a mean monthly value. Mortality from cardiovascular and respiratory causes constituted $57 \%$ of all cause mortality for people of $\geqslant 65$. Cardiovascular deaths occurred about four times more often than respiratory deaths; however, for emergency hospital admissions cardiovascular events were only about three times as common as respiratory events in the $\geqslant 65$ age group, and had about the same frequency at ages $<65$.

Hospital admissions and pollution concentrations varied according to the day of the week. For pollutants other than $\mathrm{O}_{3}$ and black smoke, concentrations on Saturdays and Sundays were generally lower at about $90 \%$ and $75 \%$ of those on Mondays to Fridays. However $\mathrm{O}_{3}$ had substantially higher concentrations on Sundays than other days. Weekend admission rates for cardiovascular, respiratory, and all emergency admissions were about 30\% lower than those on weekdays.

\section{CORRELATIONS BETWEEN POLLUTANTS AND} METEOROLOGICAL VARIABLES

Correlations of average concentrations of daily pollutants with one another and with minimum temperature and wind speed (all for the same day) were calculated. Corresponding correlations were also calculated separately for the winter (October to March) and summer (April to September) seasons, and first order partial correlations between the variables adjusting for all the 33 months of the short period as dummy variables.

Concentrations of $\mathrm{NO}_{2}$ had a large negative correlation with those of $\mathrm{O}_{3}$ and large positive correlations with $\mathrm{PM}_{10}, \mathrm{SO}_{2}$ and $\mathrm{CO}$ and were generally similar in winter and summer; $\mathrm{O}_{3}$ was negatively correlated with the pollutants. In winter the $\mathrm{O}_{3}$ correlation with $\mathrm{PM}_{10}$ was -0.6 , but in summer it was +0.1 , and after adjusting

Table 3 Change (\%) in risk of emergency hospital admissions associated with increases in air pollution as a moving average of the previous 3 days

\begin{tabular}{|c|c|c|c|c|c|c|c|c|}
\hline & \multicolumn{4}{|l|}{ Age $\geqslant 65$} & \multicolumn{4}{|l|}{ Age $<65$} \\
\hline & \multicolumn{2}{|c|}{ Cardiovascular admissions } & \multicolumn{2}{|c|}{ Respiratory admissions } & \multicolumn{2}{|c|}{ Cardiovascular admissions } & \multicolumn{2}{|c|}{ Respiratory admissions } \\
\hline & $\begin{array}{l}\text { Increase } \\
(\%)\end{array}$ & $95 \% C I$ & $\begin{array}{l}\text { Increase } \\
(\%)\end{array}$ & $95 \% C I$ & $\begin{array}{l}\text { Increase } \\
(\%)\end{array}$ & $95 \% C I$ & $\begin{array}{l}\text { Increase } \\
(\%)\end{array}$ & $95 \% C I$ \\
\hline \multicolumn{9}{|l|}{ Long series 1981-95: } \\
\hline \multicolumn{9}{|l|}{ Black smoke $\left(10 \mu \mathrm{g} / \mathrm{m}^{3} ; \mathrm{P} 90-\mathrm{P} 10=22\right.$} \\
\hline 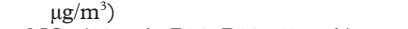 & -0.2 & -1.5 to 1.2 & -1.3 & -3.4 to 0.8 & -0.2 & -2.2 to 1.8 & -0.5 & -2.5 to 1.5 \\
\hline $\mathrm{NO}_{2}(10 \mathrm{ppb} ; \mathrm{P} 90-\mathrm{P} 10=17 \mathrm{ppb})$ & -0.6 & -2.5 to 1.1 & -0.3 & -3.3 to 2.5 & -0.1 & -3.0 to 2.7 & -0.1 & -3.0 to 2.6 \\
\hline \multicolumn{9}{|l|}{ Short series 1992-5: } \\
\hline $\begin{array}{l}\text { Black smoke }\left(10 \mu \mathrm{g} / \mathrm{m}^{3} ; \mathrm{P} 90-\mathrm{P} 10=15\right. \\
\left.\mu \mathrm{g} / \mathrm{m}^{3}\right)\end{array}$ & 2.3 & -1.9 to 6.9 & 3.1 & -3.5 to 10.2 & -3.9 & -10.7 to 3.4 & -5.0 & -11.2 to 1.7 \\
\hline $\mathrm{PM}_{10}\left(10 \mu \mathrm{g} / \mathrm{m}^{3} ; \mathrm{P} 90-\mathrm{P} 10=20 \mu \mathrm{g} / \mathrm{m}^{3}\right)$ & 4.8 & 0.9 to $8.9^{\star}$ & 2.1 & -3.8 to 8.4 & 0.8 & -5.2 to 7.2 & 0.5 & -5.3 to 6.7 \\
\hline $\mathrm{SO}_{2}(10 \mathrm{ppb} ; \mathrm{P} 90-\mathrm{P} 10=12 \mathrm{ppb})$ & 4.9 & -1.0 to 11.1 & -2.5 & -11.0 to 6.9 & -3.7 & -12.4 to 5.9 & 0.0 & -8.3 to 9.1 \\
\hline $\mathrm{NO}_{2}(10 \mathrm{ppb} ; \mathrm{P} 90-\mathrm{P} 10=17 \mathrm{ppb})$ & -0.5 & -5.2 to 4.5 & 3.1 & -4.6 to 11.5 & -0.9 & -8.2 to 7.0 & -0.2 & -7.5 to 7.7 \\
\hline $\mathrm{O}_{3}(10 \mathrm{ppb} ; \mathrm{P} 90-\mathrm{P} 10=17 \mathrm{ppb})$ & -5.9 & -11.4 to $-0.1^{\star}$ & 0.9 & -8.4 to 11.1 & 4.1 & -5.4 to 14.4 & -2.9 & -11.5 to 6.8 \\
\hline $\mathrm{CO}(100 \mathrm{ppb} ; \mathrm{P} 90-\mathrm{P} 10=500 \mathrm{ppb})$ & 1.1 & -0.1 to 2.4 & 0.0 & -2.0 to 2.0 & -1.4 & -3.4 to 0.7 & 1.0 & -0.9 to 3.0 \\
\hline
\end{tabular}

$\star=0.01<\mathrm{p}<0.05$.

$\mathrm{P} 90-\mathrm{P} 10=$ the 10 th to 90 th percentile range.

Risk estimates adjusted for month (33 categories for short series or 174 categories for long series) to minimum temperature (8 categories) and wind speed and day of the week ( 7 categories). 
Table 4 Changes (\%) in cardiovascular and respiratory emergency admissions for the $\geqslant 65$ age group with increments in pollutants (PM $10.10 \mu g / m^{3}$, $\mathrm{O}_{3}: 10 \mathrm{ppb}$ ) as moving means of the 3 previous days by admissions subgroup 1992-5

\begin{tabular}{|c|c|c|c|c|c|c|c|c|c|}
\hline \multirow[b]{2}{*}{ Cause } & \multirow[b]{2}{*}{ Pollutant } & \multicolumn{2}{|c|}{ All admissions } & \multicolumn{2}{|c|}{$\begin{array}{l}\text { All admissions for subjects } \\
\text { with }>1\end{array}$} & \multicolumn{2}{|c|}{$\begin{array}{l}\text { All admissions for subjects } \\
\text { with }>2\end{array}$} & \multicolumn{2}{|c|}{$\begin{array}{l}\text { All admissions for subjects } \\
\text { with }>4\end{array}$} \\
\hline & & $\begin{array}{l}\text { Increase } \\
(\%)\end{array}$ & $95 \% C I$ & $\begin{array}{l}\text { Increase } \\
(\%)\end{array}$ & $95 \% C I$ & $\begin{array}{l}\text { Increase } \\
(\%)\end{array}$ & $95 \% C I$ & $\begin{array}{l}\text { Increase } \\
(\%)\end{array}$ & $95 \% C I$ \\
\hline \multirow[t]{2}{*}{ Cardiovascular } & $\mathrm{PM}_{10}$ & 4.8 & 0.9 to $8.9^{\star}$ & 6.4 & 1.2 to $11.9^{\star}$ & 4.5 & -2.0 to 11.5 & -2.2 & -11.5 to 8.2 \\
\hline & $\mathrm{O}_{3}$ & -5.9 & -11.4 to $-0.1^{\star}$ & -2.5 & -10.0 to 5.5 & 4.3 & -5.8 to 15.6 & 5.3 & -10.2 to 23.3 \\
\hline \multirow[t]{2}{*}{ Respiratory } & $\mathrm{PM}_{10}$ & 2.2 & -3.8 to 8.4 & 0.6 & -7.0 to 8.9 & 1.7 & -7.2 to 11.5 & 3.1 & -8.1 to 15.6 \\
\hline & $\mathrm{O}_{3}$ & 0.9 & -8.4 to 11.1 & 1.2 & -10.7 to 14.8 & -5.8 & -18.6 to 9.0 & -9.1 & -24.1 to 9.0 \\
\hline
\end{tabular}

$\star=0.01<\mathrm{p}<0.05$

The emergency admissions included here for the short series, October 1992 to June 1995, are for subjects having $>0$, $>1,>2$, and $>4$ emergency admissions of the same type between January 1981 and June 1995.

for within month variations the (partial) correlation was -0.3 . Correlations with black smoke behaved similarly. Concentrations of $\mathrm{PM}_{10}$ showed only a moderate association $(0.4)$ with those of black smoke, of roughly the same strength as that found in London. ${ }^{16}{ }^{17}$ There were high positive correlations of $\mathrm{PM}_{10}$ with $\mathrm{NO}_{2}, \mathrm{SO}_{2}$, and $\mathrm{CO}$, in winter and within months, but in summer these correlations were less marked. Concentration of $\mathrm{PM}_{10}$ was negatively correlated with wind speed $(-0.4)$, and had a weak negative correlation with minimum temperature. $\mathrm{SO}_{2}$ and $\mathrm{CO}$ were both strongly correlated with the other pollutants.

POLLUTANT EFFECTS ASSOCIATED WITH ALL CAUSE MORTALITY

Figure $2 \mathrm{~A}$ and $\mathrm{B}$ show the results of models for all cause mortality in the older and younger age groups for both the long and the short period. Each horizontal line in the figure shows the estimated effects and 95\% confidence intervals (95\% CIs) when each pollutant, as a moving mean of the three previous days, was separately added to the core model. The core model contained terms for month, minimum temperature, and wind speed, but not for day of the week as this showed little association with mortality. Results for pollutants at lags 0 (same day) and 1 (previous day) have not been shown.

The most significant finding $(\mathrm{p}<0.001)$ was an association between black smoke as a mean of the previous 3 days and an increase in all cause mortality in people aged $\geqslant 65$. For an increment of $10 \mu \mathrm{g} / \mathrm{m}^{3}$ in the mean of black smoke over the previous three days there was an estimated increase of $1.5 \%$ (95\% CI 0.5 to $2.5)$ in all cause mortality in the $\geqslant 65$ age group compared with $1.6 \%(-0.5$ to 3.7$)$ in the younger age group. Somewhat smaller associations of moderate significance $(p<0.05)$ were found for same day black smoke.

Findings for $\mathrm{SO}_{2}$ were inconsistent. Over the long period, same day $\mathrm{SO}_{2}$ was associated with a significant decrease of $-2.4 \%(-4.6$ to -0.1$)$ in all cause mortality in the younger age group for a $10 \mathrm{ppb}$ increment in daily average concentration. Each of these associations remained significant after adjusting for black smoke measured over the long period. In the short time series, for $\mathrm{SO}_{2}$ (measured by UV fluorescence) a $10 \mathrm{ppb}$ increment on the same day was linked to a $4.2 \%(0.1 \%$ to $8.4 \%)$ increase in all cause mortality in the $\geqslant 65$ age group, but this was no longer significant after adjusting for the effects of other pollutants.

Increments in $\mathrm{CO}$ and $\mathrm{O}_{3}$ on the same day were significantly associated with all cause all age mortality (CO (100 ppb) $0.8 \%$ (0.1 to 1.5$)$, and $\mathrm{O}_{3}(10 \mathrm{ppb})-4.2 \%(-8.1$ to -0.1$\left.)\right)$. In the $<65$ age group increments of $10 \mathrm{ppb}$ in $\mathrm{NO}_{2}$ and $\mathrm{O}_{3}$ on the same day were significantly associated with increases in all cause mortality of $8.5 \%(0.9 \%$ to $16.9 \%)$ and $-11.7 \%(-20.1 \%$ to $-2.3 \%)$, respectively. However, none of these associations remained significant after adjusting for effects of the other pollutants.

\section{POLLUTANT EFFECTS ASSOCIATED WITH}

CARDIOVASCULAR AND RESPIRATORY MORTALITY In the long series the most significant association was a notable $3.9 \%(1.1 \%$ to $6.8 \%)$ increase in respiratory mortality in the $\geqslant 65$ age group for an increment of $10 \mu \mathrm{g} / \mathrm{m}^{3}$ in the mean of the three previous days of black smoke. Results are given in figure $3 \mathrm{~A}$ and $\mathrm{B}$ for cardiovascular and respiratory mortality. In the short series, increments in the pollutants were not associated with significant increments in cardiovascular or respiratory mortality in this age group. On average there was less than one death per day from cardiovascular and from respiratory causes in the $<65$ age group and hence results from these models have not been presented.

POLLUTANT EFFECTS ASSOCIATED WITH HOSPITAL ADMISSIONS

The influences of sequential inclusion of the confounders into the core model for the effects of one pollutant are shown in table 2. Day of the week was the most influential confounder for emergency admissions. The estimated effects of each pollutant (as a mean of the previous 3 days) on emergency hospital admissions for cardiovascular and respiratory disease in each age group for both the long and the short periods are shown in table 3. The core model contained terms for weekday, month, minimum temperature, and wind speed. Without adjusting for multiple testing there was a significant increase of $4.8 \%(0.9 \%$ to $8.9 \%)$ in cardiovascular emergency admissions for ages $\geqslant 65$ in response to an increment of $10 \mu \mathrm{g} / \mathrm{m}^{3}$ in the 3 day moving mean of $\mathrm{PM}_{10}$. An increment of $10 \mathrm{ppb}$ in the 3 day moving mean of $\mathrm{O}_{3}$ was associated with a significant decrease of $-5.9 \%$ $(-11.4 \%$ to $-0.1 \%)$ in cardiovascular admissions over age 65 . Each of these associations was still significant and of similar magnitude 
after adjustment for all other pollutants. There were no significant associations with black smoke, $\mathrm{SO}_{2}, \mathrm{NO}_{2}$, or CO.

When the analysis of emergency admissions was repeated with people categorised by number of emergency admissions, no consistent patterns were found for the long time series. Cardiovascular and respiratory admissions were analysed separately within these categories with $\mathrm{PM}_{10}$ and $\mathrm{O}_{3}$ as 3 day moving means over the short period and are shown in table 4.

\section{Discussion}

This is the longest published time series study of urban air pollution in Britain of which we are aware and the most notable conclusion is the association between concentrations of particulate air pollution and respiratory mortality in the $\geqslant 65$ age group. In studies of this type it is essential to take account of important confounding variables. Thus it is known that cold temperature is a significant determinant of cardiovascular mortality ${ }^{18}$ and that additionally the influence of wind speed will account for a further proportion of variation, at least for mortality. ${ }^{19}$ Moreover, additional confounders may influence emergency hospital admissions. Thus the data showed a remarkable variance associated with day of the week for emergency hospital admissions. One explanation might be that day of the week determines pollutant concentrations and that this in turn determines the likelihood of emergency hospital admissions. However, social aspects, in particular the likelihood of seeking medical advice, or the medical admission policy, at or around the weekend, may be important determinants of the emergency hospital admission rate in a manner not directly dependent on pollution. This explanation was more plausible with this data as the association between day of the week and emergency hospital admission rates seemed to apply even to diseases other than cardiac and respiratory, for which a causal relation with pollution was an original hypothesis. Moreover, the stepwise introduction of terms in the model (table 2) resulted in the largest proportion of the explicable variance when day of the week was accounted for, although the time of year was also a confounder, and the relation between weather, notably minimum temperature, and ill health is also important. ${ }^{20}$

The study has similarities in the data collection (pollutants, confounders, and health outcomes) and in the analyses and results with those of other studies, especially from the other two United Kingdom conurbations which have been reported on so far. ${ }^{45}$ As with all time series studies based on routinely collected data, the validity of the data set is an important consideration. In common with other studies of this type, which have applied a single point measurement of pollutants as an average exposure for a large area of residence it is likely to underestimate the effects of specific concentrations of pollutants on health. ${ }^{21}$ This can happen because the most important exposure estimate-namely, that of personal exposures - was not available. The assumption is thus made that personal exposure correlates closely with fixed point sampling, and secondly that other physical factors such as temperature are treated as confounders. The first assumption is certainly questionable. ${ }^{22}$ It is also plausible that meteorological factors may be important determinants of personal exposure concentrations, by their influence on patterns of personal activity (indoors versus outdoors) and by affecting dispersion and deposition processes of pollutants, besides possible effects on the body's clearance of pollution or response to it.

The study focuses on a smaller urban population than some previous United Kingdom reports, ${ }^{59}$ and therefore may have had less statistical power. However, the duration of the time series (at least for two of the pollutants) was intended to help offset this. Indeed this study is longer than the maximum and at least twice the median duration of the APHEA mortality study based on 12 European cities. ${ }^{23}$ The standard error of the estimated coefficient of the pollution term is roughly inversely proportional to the square root of the total number of events in the data set multiplied by the SD of the pollution measurements. For example, London studies ${ }^{5}$ had about 4.8 times as many deaths as found in Edinburgh over our long (14.5 year) series. However, as the Edinburgh data had greater variation in black smoke and $\mathrm{SO}_{2}$ concentrations over a longer period, our $95 \%$ CIs for effects associated with these pollutants were not more than $25 \%$ wider than the London study $(95 \%$ CIs for percentage changes in all cause mortality with $10 \mu \mathrm{g} / \mathrm{m}^{3}$ increments in black smoke and $10 \mathrm{ppb}$ increments in $\mathrm{SO}_{2}$, respectively, on the previous day, were in Edinburgh (0.6 to 2.4) and ( -1.0 to $0.9)$ and in London (0.6 to 1.8$)$ and (0.0 to 1.9)). In common with most other studies in this field we have made no formal correction for multiple testing, although our tables and figures embody many (non-independent) estimates of the magnitudes of associations between pollutants and ill health and thus our $\mathrm{p}$ values and $95 \%$ CIs need to be interpreted with caution.

There are some important comparisons between this study and others, and these will be considered in turn. The overall levels of pollutants experienced were lower than those previously reported in other British cities where similar studies have been reported, Birmingham and London, ${ }^{45}$ although the interrelations between the pollutants were generally similar. However, although the Edinburgh study showed a negative correlation between $\mathrm{O}_{3}$ and $\mathrm{NO}_{2}$ concentrations in the summer $(-0.5)$ this contrasted with the positive correlation found in London. ${ }^{8}$ Explanation for this may lie in the complex concentration dependent interaction between $\mathrm{NO}_{2}$ and $\mathrm{O}_{3} .{ }^{16}{ }^{24}$

Within the limits of the power of the study, the findings especially for mortality are consistent with an effect of urban air pollution on health being of the same order as in previously published reports, ${ }^{54}$ and with a central trend probably more consistent with European than with North American studies. ${ }^{25}$ The increases 
in all cause mortality with a $10 \mu \mathrm{g} / \mathrm{m}^{3}$ increment in black smoke over the 14.5 year series in Edinburgh as a mean of the previous 3 days was $1.5 \%$ ( 0.6 to 2.4 ) and in London on the previous day was $1.2 \%$ (0.6 to 1.8 ). Changes with similar increments in $\mathrm{PM}_{10}$ as a mean of the previous 3 days in Edinburgh and Birmingham were $0.1 \%$ ( -2.8 to 3.0$)$ and $0.6 \%$ ( -0.6 to 1.9), respectively. The association between particulate air pollution and all cause mortality reported in western European cities by Katsouyanni et $a l^{23}(0.6 \%$ (0.4 to 0.8$)$ for a 10 $\mu \mathrm{g} / \mathrm{m}^{3}$ increment in black smoke) was not characterised by specific cause of death in that collaborative report, nor significantly associated with specific cause mortality by Anderson et $a l,{ }^{8}$ who found an increase in respiratory mortality with a $10 \mu \mathrm{g} / \mathrm{m}^{3}$ increment in black smoke on the previous day of $0.4 \%$ ( -1.1 to 2.0$)$, in one of the participating centres. However, our data suggest that this excess mortality specifically includes a significant contribution from respiratory disease especially in elderly people. It was most significantly related to black smoke pollution lagged over the previous 3 days, and might have been particularly influenced by the higher pollution concentrations in the earlier part of the study period. This effect was not found in the more recent short time series when particulate pollution had abated appreciably (fig 1 ). In this our findings are consistent with those reported from Birmingham ${ }^{4}$ where small but significant associations were found between mortality from circulatory causes ( $1.7 \%$ (0.2 to 3.2$)$ in Birmingham on the previous day and $2.6 \%$ (-1.4 to 7.0$)$ in Edinburgh on the same day for a $10 \mu \mathrm{g} / \mathrm{m}^{3}$ increment) or chronic pulmonary diseases and $\mathrm{PM}_{10}$ with different lags. Moreover, our study did not show a significant association with cardiac mortality.

For particulate air pollution a significant association was shown between exposure to $\mathrm{PM}_{10}$, but not black smoke (as a mean of previous 3 days) and emergency cardiovascular admissions in elderly people (table 2). This compares with studies showing an association between acute myocardial infarction, and angina pectoris with the previous day's particulate pollution, but which was shown with black smoke. ${ }^{9}$ However, with the same exposure metric with the same time lag-namely, $\mathrm{PM}_{10}$ - as a moving mean of the previous 3 days, the results for admissions due to ischaemic heart disease in Birmingham ${ }^{4}$ showed no significant effect. Our findings are consistent with extant hypotheses on the effect of particulate exposure on thrombotic mechanisms. ${ }^{26}$ Apparent differences in associations of ill health with black smoke and with $\mathrm{PM}_{10}$ warrant further comment. The difference between $\mathrm{PM}_{10}$ and black smoke cannot be merely expressed in terms of particle size distribution, or translated by a simple coefficient, and mass concentrations of particles have serious limitations when used as an exposure metric. ${ }^{27}$ The relation between $\mathrm{PM}_{10}$ and black smoke may vary geographically and seasonally, whereas $\mathrm{PM}_{10}$ measurements are likely to incorporate compounds such as sulphates and ammonium salts. ${ }^{28}$ Measurement of black smoke was the norm in the studies of United Kingdom data dating back to the 1950 s at concentrations of pollution which were much higher than those today, and therefore measurement of black smoke currently is important to establish the consistency or otherwise of exposure-response relations over the decades.

The London time series ${ }^{9}$ investigating the 7 year interval from 1987-94 presented data on pollutants lagged by 1 day and showed highly significant associations between concentrations of black smoke, $\mathrm{NO}_{2}, \mathrm{CO}, \mathrm{SO}_{2}$, and daily hospital admissions for cardiovascular disease. Our 95\% CIs for a $10 \mathrm{ppb}$ increment in the respective pollutants with the same time lag, but for age $\geqslant 65$ rather than all ages, overlapped with those found by Polonecki et al (given in parentheses). Thus for $\mathrm{SO}_{2}$ : long series $0.4 \%(-0.1$ to 1.8$)$ and short series $1.8 \%(-2.6$ to 6.4$)$, ( $1.3 \%(0.3$ to 2.3$)) ; \mathrm{NO}_{2}:-0.8 \%$ ( -4.5 to 3.2$)$, $(0.8 \%(0.2$ to 1.5$)) ; \mathrm{O}_{3}:-1.0 \%$ ( -5.5 to 3.8$)$, $(-1.1 \%(-2.3$ to 0.2$))$; $\mathrm{CO}: 0.1 \%$ ( -0.8 to $1.1),(0.2 \%(0.1$ to 0.4$))$. Therefore the London results and the Edinburgh series reported here are not generally inconsistent in the findings for these pollutants or for $\mathrm{O}_{3}$ given the respective $95 \%$ CIs although the central trend does suggest an effect shown in London, but not in Edinburgh which might be attributed to differences in the pollution experience of the two cities. The fewer cardiovascular events in Edinburgh did not permit as detailed an analysis of subgroups of diagnostic codes.

This study showed a significant negative association between emergency cardiovascular admissions in elderly people and the moving mean of $\mathrm{O}_{3}$ concentration over the previous 3 days. This contrasts with the findings of Ponce de Leon $e t a \bar{P}$ who had shown a positive albeit small association between $\mathrm{O}_{3}$ concentrations and respiratory admissions. These apparent inconsistencies may be the result of differences in the relations between $\mathrm{O}_{3}$ and $\mathrm{NO}_{2}$ concentrations that operate in the two cities with markedly different area and pollution loads. Thus in urban centres, $\mathrm{NO}$ is the primary emitted oxide of nitrogen and it generates $\mathrm{NO}_{2}$ by reacting with $\mathrm{O}_{3}$, leading to a generally reciprocal relation between $\mathrm{NO}_{2}$ and $\mathrm{O}_{3}{ }^{24}$ However, in conditions of high photochemical generation of $\mathrm{O}_{3}$ in lower latitudes than Edinburgh and with high emissions of primary pollutants, ${ }^{24}$ concentrations of $\mathrm{NO}_{2}$ can also occur together with high concentrations of $\mathrm{O}_{3}$. The urban gradient of decreasing $\mathrm{NO}_{2}$ and increasing $\mathrm{O}_{3}$ is influenced by the rate of generation of the primary pollutants, sunlight, and other factors. The central estimate at the fixed sampling point is therefore probably an inaccurate reflection of the absolute values or the ratios of the agents to which most of the population is exposed. This shortcoming cannot necessarily be remedied by statistical techniques without geographically wider ranging measurements of exposure. $\mathrm{NO}_{2}$ might also exert an additional important influence through indoor exposure from cooking ${ }^{29}$ and this concentration would not be reflected in outdoor measurements. 
The linkage of the Scottish (health) data set ${ }^{13}$ was exploited in this study to determine whether people with multiple emergency cardiovascular or respiratory admissions might be more susceptible to the influence of air pollution. These data do not lend support to such a hypothesis although it is acknowledged that a cohort study design (in progress) would be better suited to consider the fundamental issue of any determinants of susceptibility to the health effects of air pollution.

In summary these data present weaker evidence of association between urban air pollution and cardiorespiratory ill health than has generally been reported, but in common with most other studies has the drawback of a single city centre sampling point. ${ }^{21}$ It is likely that better estimates of exposure will be forthcoming through the use of personal sampling techniques or multiple sampling points and spatial modelling as well as studies focusing on possible susceptible groups. Such work is in progress and may give more reliable estimates of any causal associations between air pollution and health.

RMA received funding from the Department of Health. The views expressed in this publication are those of the authors and not necessarily those of the Department of Health. We thank D Beverland, Dr M Heal, and Professor D Fowler, for advice and for comments on the manuscript. We acknowledge the help of Dr S Kendrick of the Scottish Health Service Information and Statistics Division in providing mortality and morbidity data and AEA Technology in supplying the collated and validated urban air pollution data. We are particularly grateful to the City of Edinburgh Environmental and Consumer Services Department, and especially Mr T Bell, Mr G Greenhill, and Dr A smoke and $\mathrm{SO}_{2}$, and for continuing collaboration in this field.

1 Dockery DW, Pope III CA, Xu X, et al. An association between air pollution and mortality in six US cities. $N$ Engl fMed 1993;329:1753-9.

2 Katsouyanni K, Karakatsani A, Messari I, et al. Air pollution and cause specific mortality in Athens. $\mathcal{F}$ Epidemiol Community Health 1990;44:321-4.

3 Walters S, Griffiths RK, Ayres JG. Temporal association between hospital admissions for asthma in Birmingham and ambient levels of sulphur dioxide and smoke. Thorax 1994:49:133-40.

4 Wordley J, Walters S, Ayres JG. Short term variations in hospital admissions and mortality and particulate air pollution. Occup Environ Med 1997;54:108-16.

5 Ponce de Leon A, Anderson HR, Bland JM, et al. Effects of air pollution on daily hospital admissions for respiratory disease in London between 1987-8 and 1991-2 (APHEA Project-European Approach). I Epidemiol Community Health 1996;50(suppl 1):S63-70

6 The United Kingdom National Air Quality Strategy. London: The Stationary Office, 1997.

7 Brunekreef B. Air pollution and life expectancy: is there a relation? Occup Environ Med 1997;54:781-4.
8 Anderson HR, Ponce de Leon A, Bland JM, et al. Air pollution and daily mortality in London: 1987-92. BMF 996;312:665-9.

9 Poloniecki JD, Atkinson RW, Ponce de Leon A, et al. Daily time series for cardiovascular hospital admissions and previous day's air pollution in London, UK. Occup Environ Med 1997;54:535-40.

10 Determination of a black smoke index. London: British Standards Institution, 1993. (BS 1747 Part 11.)

11 Determination of a gaseous acid air pollution index - titrimetric method with indicator or potentiometric end-point detection. London: British Standards Institution, 1969. (BS 1747 Part 3.)

12 Quality of Urban Air Review Group (QUARG). Urban air quality in the United Kingdom. First Report of the Quality of Urban Air Review Group. Prepared at the request of the Department of the Environment. DOE, PO Box 135, Bradford, UK, 1993.

13 Kendrick S, Clarke J. The Scottish record linkage system. Health Bull (Edinb) 1993;51:72-9.

14 Schwartz J. Air pollution and hospital admissions for the elderly in Detroit, Michigan. Am f Respir Crit Care Med 1994;150:648-55

15 McCullagh P, Nelder JA. Generalized linear models. London: Chapman and Hall, 1983.

16 Quality of Urban Air Review Group (QUARG). Airborne particulate matter in the United Kingdom. 3rd Report of the particulate matter in the United Kingdom. 3rd Report of the Birmingham: prepared at the request of the Department of Environment. University of Birmingham, Institute of Public and Environmental Health, School of Chemistry, 1996.

17 Committee on the Medical Effects of Air Pollutants COMEAP). Non-biological particles and health. London: HMSO, 1995.

18 Wilmshurst P. Temperature and cardiovascular mortality: excess deaths from heart disease and stroke in northern Europe and due in part to the cold. BMF 1994;309:102930.

19 Kunst AE, Groenhof F, Mackenbach JP. The association between two windchill indices and daily mortality variation in The Netherlands. Am f Public Health 1994;84:1738-42.

20 Schwartz J. What are people dying of on high air pollution days? Environ Res 1994;64:26-35.

21 Krzyzanowski $M$. Methods for assessing the extent of exposure and effects of air pollution. Occup Environ Med 1997; 54:145-51.

22 Watt $\mathrm{M}$, Godden $\mathrm{D}$, Cherrie J, et al. Individual exposure to particulate air pollution and its relevance to thresholds for health effects: a study of traffic wardens. Occup Environ Med 1995;52:790-2.

23 Katsouyanni K, Touloumi G, Spix C, et al. Short term effects of ambient sulphur dioxide and particulate matter on mortality in 12 European cities: results from time series data from the APHEA project. BMF 1997;314:1658-63.

24 Photochemical Oxidants Review Group (PORG). Ozone in the United Kingdom. 3rd Report of the Photochemical Oxidants Review Group. London: Prepared at the request of the Department of the Environment, 1995.

25 Schwartz J. Air pollution and daily mortality: a review and meta analysis. Environ Res 1994;64:36-52.

26 Seaton A, MacNee W, Donaldson K, et al. Particulate air pollution and acute health effects. Lancet 1995;345:17678 .

27 Dockery DW, Pope CA. Acute respiratory effects of particulate air pollution. Annu Rev Public Health 1994;15:107-32.

28 Harrison RM, Smith DI, Luhana L. Source apportionment of atmospheric polycyclic aromatic hydrocarbons collected from an urban location in Birmingham, UK. Environmental Science and Technology 1996;30:825-32.

29 Committee on the Medical Effects of Air Pollution and Health (COMEAP). Handbook on air pollution and health. London: HMSO, 1997. 